J. Biosci., Vol. 21, Number 6, December 1996, pp 827-841. (C) Printed in India.

\title{
Embryogenesis in flowering plants: Recent approaches and prospects
}

\author{
K SANKARA RAO* \\ Department of Biochemistry, Indian Institute of Science, Bangalore 560012, India \\ MS received 14 May 1996; revised 3 September 1996
}

\begin{abstract}
The overall architectural pattern of the mature plant is established during embryogenesis. Very little is known about the molecular processes that underlie embryo morphogenesis. Last decade has, nevertheless, seen a burst of information on the subject. The synchronous somatic embryogenesis system of carrot is largely being used as the experimental system. Information on the molecular regulation of embryogenesis obtained with carrot somatic embryos as well as observations on sandalwood embryogenic system developed in our laboratory are summarized in this review. The basic experimental strategy of molecular analysis mostly relied on a comparison between genes and proteins being expressed in embryogenic and non-embryogenic cells as well as in the different stages of embryogenesis. Events such as expression of totipotency of cells and establishment of polarity which are so critical for embryo development have been characterized using the strategy. Several genes have been identified and cloned from the carrot system. These include sequences that encode certain extracellular proteins (EPs) that influence cell proliferation and embryogenesis in specific ways and sequences of the abscisic acid (ABA) inducible late embryogenesis abundant (LEA) proteins which are most abundant and differentially expressed mRNAs in somatic embryos. That LEAs are expressed in the somatic embryos of a tree flora also is evidenced from studies on sandalwood. Several undescribed or novel sequences that are enhanced in embryos were identified. A sequence of this nature exists in sandalwood embryos was demonstrated using a Cuscuta haustorial (organspecific) cDNA probe. Somatic embryogenesis systems have been used to assess the expression of genes isolated from non-embryogenic tissues. Particular attention has been focused on both cell cycle and histone genes.
\end{abstract}

Keywords. Embryogenesis; extracellular proteins; LEA proteins; molecular regulation; novel nucleotide sequences; synchrony.

\section{Introduction}

The dominant sporophyte of higher plants is initiated with the double fertilization event that results in the formation of a single-celled zygote and a primary endosperm cell, the precursor of endosperm. The zygote soon acquires the potential to develop into an embryo and undergoes a complex series of morphological and cellular changes, the mechanisms in the establishment of the polarity, the differentiation of the tissue systems and the elaboration of the pattern that ultimately carries each species of higher plants to the next generation all being at work during embryogenesis.

The first asymmetric division of the zygote yields a basal cell that will produce most part of the so-called suspensor and an apical cell that gives rise to the embryo (figures 1-14). After eight cell stages, anticlinal divisions of the surface cells mark the

*Fax, 091-80-341814; Email, baradwaji@biochem.iisc.ernet.in. 

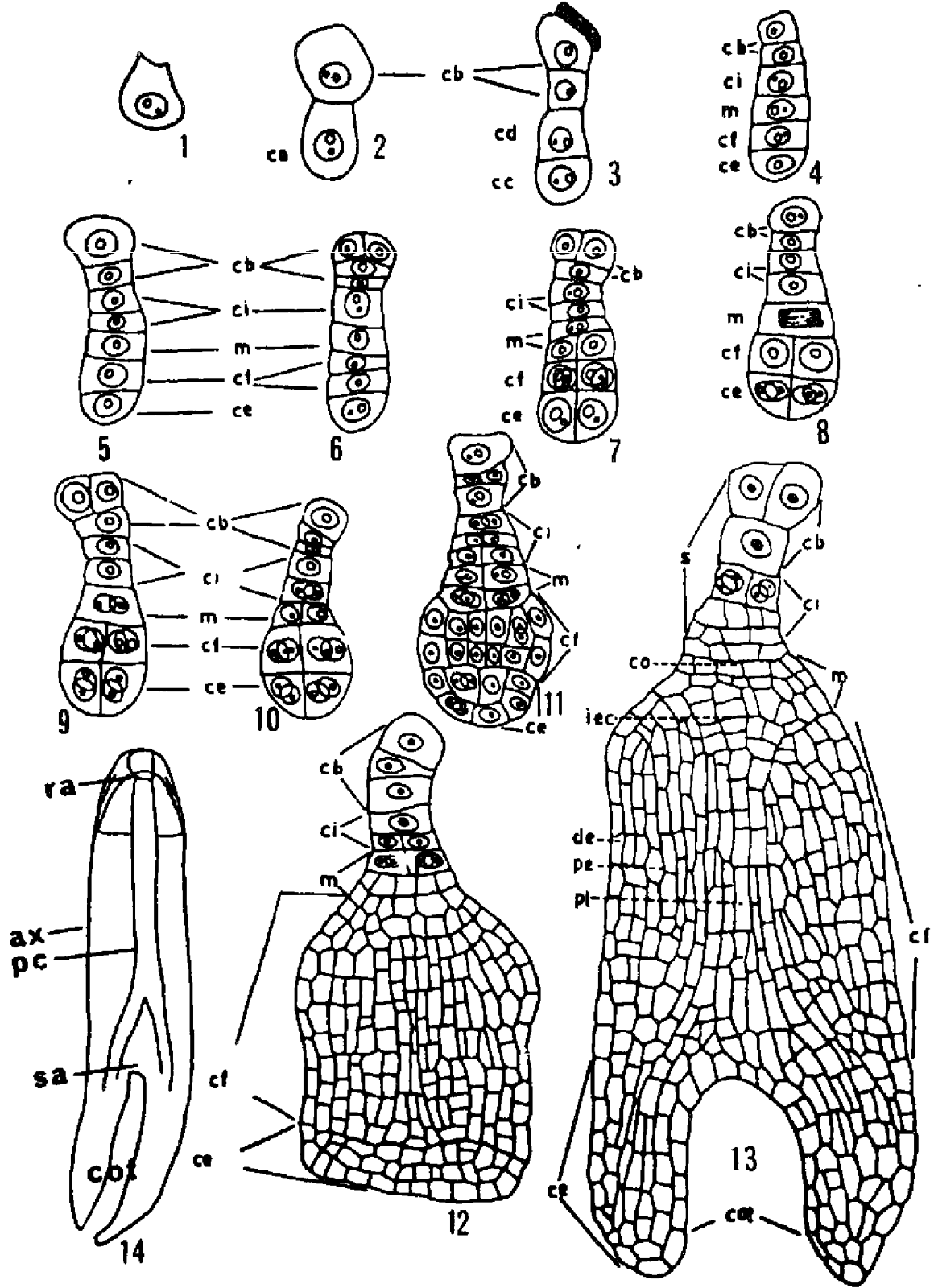

Figures 1-14. Development of zygotic embryo in Gentiana pedicellata Wall. 1. Zygote. 2. Two-celled proembryo. 3. Proembryonal tetrad. 4-6. Six to eight-celled proembryos. 7-10. Proembryo showing the formation of tiers ce, cf, m, ci. 11. Stage of embryo showing the beginning of the histogen demarcation, particularly, the dermatogen (protoderm). 12. Heartstage embryo showing the initials of the vascular tissues, the plerome (procambium). 13-14. Torpedo and cotyledon stage embryos (1-13 $\times 800 ; \mathbf{1 4}, \times 200)$,

(ax, embryonal axis; $c a$, apical cell; $c b$, basal cell, $c c$, upper daughter cell of $c a ; c d$, lower daughter cell of $c a$; $c e$, upper daughter cell of $c c, c f$, lower daughter cell of cc; $c i$, daughter cell of $c d$; co, root cap; de, dermatogen; iec, initials of root cortex; $m$, daughter cell of $c d$; $p e$, periblem; $p l$, plerome; pc, procambium; $r a$, root apex; s, suspensor; sa, shoot apex.) 
formation of the protoderm (figure 11), the embryo tissue that gives rise to epidermis. At the heart-shaped stage (figure 12), the vascular initials that connect the root and shoot apices are formed, and cotyledon development starts next to the future shoot apical meristem. The torpedo stage is characterized by cell expansion in addition to cell division and results in elongation of the embryo along the root-shoot axis. During the cotyledonary stage, cotyledons expand and are filled with storage food material.

Proliferation of the primary endosperm cell results in the endosperm that surrounds the developing embryo and enlarges the embryo sac. The endosperm is absorbed by the developing cotyledons or persists during seed maturation. Thus, the zygote and the primary endosperm cell developing into embryo and endosperm respectively within the confines of the protective maternal tissue of the ovule, represent the unique transition state in the life cycle of higher plants.

\section{Non-zygotic embryogenesis}

Non-zygotic embryo development is not uncommon and occurs in a wide range of plant species. Such somatic embryos develop either from vegetative tissues such as the leaf margin and hypocotyl epidermis or from maternal reproductive tissues such as nucellus and synergid cells. In many varieties of Citrus there is a high incidence of this asexual embryogenesis (Bacchi 1943). The ovule produces zygotic as well as nonzygotic embryos that are derived from somatic cells of the nucellus. Morphological and ultrastructural evidence indicates that non-zygotic embryos develop in a similar manner as zygotic embryos. They share the characteristic globular, heart and torpedo stages and can develop into fully differentiated plants (Williams and Maheswaran 1986).

\section{Somatic embryogenesis}

In many plant species, somatic cells of mature plant organs can be induced to proliferate in synthetic media supplemented with the plant growth regulators, auxin and cytokinin. Some of these proliferating cells are capable of producing somatic embryos that can develop into fertile flowering plants.

Since Reinert (1958) and Steward et al (1958) described somatic embryogenesis in carrot (Daucus carota L.), the number of higher plant species from which somatic embryos could be obtained has continuously increased. Some species, however, are more recalcitrant than others with respect to both initiation of embryogenic cultures and regeneration of plants.

Like their zygotic counterparts, somatic embryos have an ultimate single cell origin (Backs-Hüsemann and Reinert 1970; Nomura and Komamine 1985), but in practice, somatic embryos usually develop from clusters of embryogenic cells. Figure 16 shows cultured sandalwood (Santalum album L.) cells in clusters that can recapitulate embryo development.

The strategy most often used to elicit somatic embryogenesis is to expose excised plant tissue to a high concentration of auxin. After the released explant cells have proliferated in the presence of auxin, two main cell types can be distinguished: non-embryogenic, highly vacuolated cells (figure 15) and a second type consisting of small, embryogenic cells composed mainly of cytoplasm (figure 16). After the induction 

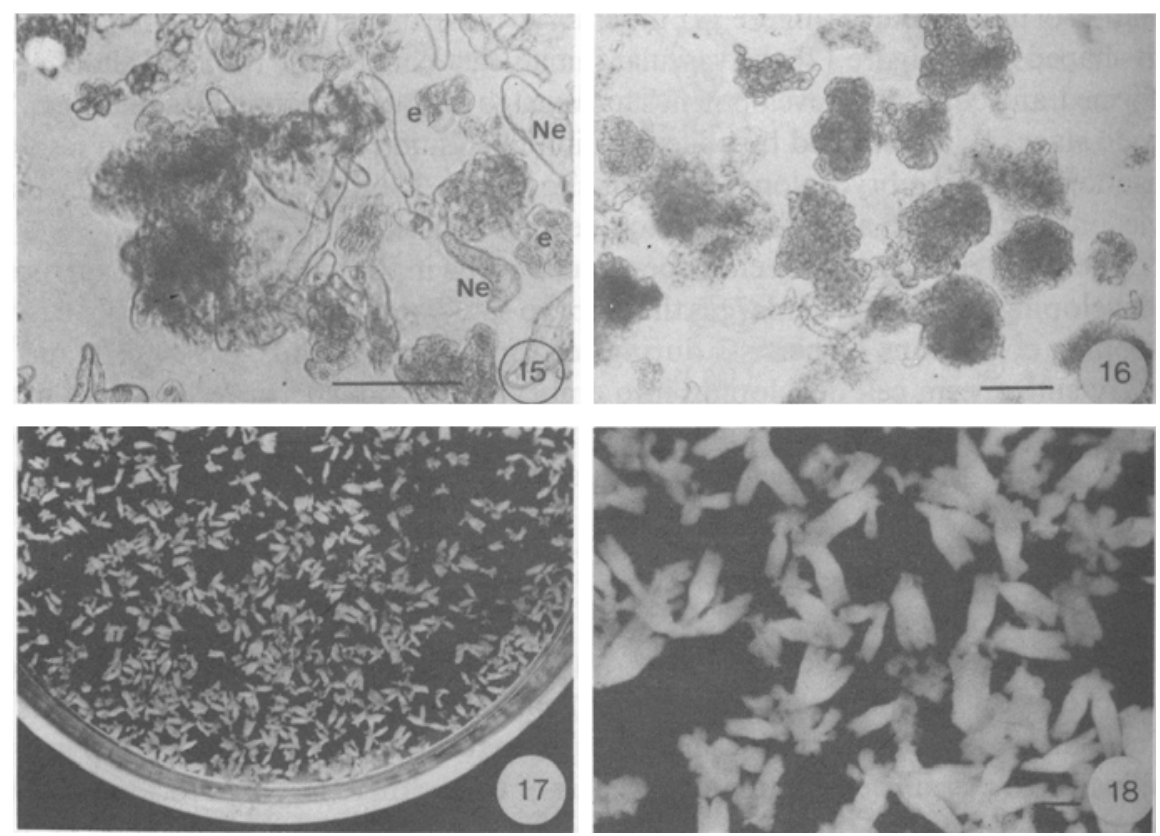

Figures 15-18. Photographs of sandalwood (Santalum album L.) cultured cells. 15. Cell population of stock suspension culture ( $\mathrm{Ne}$, non-embryogenic cells; e, embryogenic cell cluster). 16 Embryogenic cell clusters obtained after fractionation by sieving. 17. Culture showing torpedo- and cotyledon-stage embryos. 18. Torpedo-stage embryos obtained on a gelled medium. (Bar represents $100 \mu \mathrm{m}$ ).

of embryogenic phase, somatic embryos (which closely resemble their zygotic counterparts in morphology), develop from clusters of embryogenic cells in the absence of any added growth regulators (figures 17 and 18).

Although the morphology of plant embryogenesis has been extensively documented (Johri 1984; Steeves and Sussex 1989; Mayer et al 1991) through microscopy, our understanding of the molecular events that generate the plant embryo is still very limited. Molecular analyses of early embryogenesis have been hampered by the physical inaccessibility of minute early embryos which lie embedded within the confines of the protective maternal tissue of the ovule. Since somatic embryogenesis follows the same pathway of development as zygotic embryos to a substantial degree and, is not limited in tissue quantity or accessibility, it has become an ideal experimental material. Recent progress in understanding the molecular and cellular events of early embryogenesis has resulted from experiments on somatic embryogenesis of a few plant species (De Jong et al 1993; Liu et al 1993; Zimmerman 1993).

In embryogenic cultures of most species, embryogenesis proceeds in an asynchronous fashion. For example, in carrot and sandalwood (a system which was developed in our laboratory) various developmental stages and undifferentiated cell clumps are seen in the same culture at any given time after the onset of embryogenesis. This asynchrony hampers detailed biochemical and molecular investigations. Fujimura and Komamine (1979) established a system of embryogenesis in carrot suspension culture in which more than $90 \%$ of the cell clusters synchronously differentiated to embryos. The analysis of embryogenic carrot cell suspension cultures 
has proven most productive and the system remained the primary experimental model (Van Engelen and de Vries 1992; De Jong et al 1993). A major advantage of the carrot system is the relatively simple procedure with which massive amounts of staged somatic embryos can be produced under controlled conditions in liquid cultures. Recent studies (Dudits et al 1991), however, have highlighted the utility of alfalfa microcallus cells as an alternative system.

There are two possible ways for overcoming the problem of asynchrony: (i) the synchronization of embryogenesis (Fujimura and Komamine 1979) and (ii) the physical separation of embryogenic stages (Warren and Fowler 1977; Giuliano et al 1983). The physical separation, however, is not easily accomplished and is not effective unless embryogenesis occurs at high frequency.

Different protocols for obtaining staged somatic embryos have been developed and were reviewed (Lo Schiavo 1984). The protocol that was developed to obtain near synchrony of staged embryos of sandalwood which is being routinely used in our laboratory involves the following steps: (i) The establishment of a callus culture from the cultured endosperm or the shoot segments, (ii) selection of embryogenic cell clusters from 2,4-dichlorophenoxyacetic acid-treated primary cultures by sieving with a nylon screen for embryogenic suspension initiation, (iii) culture of cell clusters at a required density in a liquid medium lacking auxin and containing high osmoticum, and (iv) separation of bipolar, globular embryos and undifferentiated cell clumps by sieving and sedimentation (figures 17 and 18).

The system rendered itself useful for investigating the process of embryogenesis from embryogenic cell clusters (stage 1- $S_{1}$, globular, (stage $2-S_{2}$ ) and bipolar stage (stage3$S_{3}$ ) embryos of sandalwood. Detailed morphological observations from the carrot system in which high frequency embryogenesis was obtained with synchrony (Nomura and Komamine 1985; Komamine et al 1992) and by the use of antiauxins, 2,4,6trichlorophenoxyacetic acid and p-chlorophenoxyisobutyric acid (PCIB) on the system, at least two distinct phases can be physiologically distinguished in the differentiation of embryos from single cells. Determination for embryogenesis may occur in the first phase. Exogenous auxin was required for the determination, but once the determination occurs, auxin is inhibitory for development of the embryogenic cell clusters formed in the first phase to embryos.

There were many contradictory reports on the effects of exogenous auxin on somatic embryogenesis and auxin has been found to be inhibitory to embryogenesis in some reports (Nomura and Komamine 1985). In my study of sandalwood embryogenesis, embryogenic cell clusters were recovered from auxin (2, 4-D) pretreated primary calli. Gavish et al (1991) reported a unique phenomenon of utilization of glycerol as a carbon source and an inducer for morphogenesis in sour range (Citrus aurantium L.). The cytokinin, zeatin shows a promotive effect on embryogenesis in each phase. It is most promotive in phase 2 , in which active cell division occurs. Zeatin action may be involved in the promotion of cell division. Other phytohormones, gibberellin and abscisic acid, inhibit embryogenesis from cell clusters (Komamine et al 1992). In sandalwood, $\mathrm{GA}_{3}$ is reported to be promotive in embryogenesis. Besides phytohormones, cell-to-cell interaction is another important factor in somatic embryogenesis. A rather high cell density $\left(10^{5}\right.$ cells $\left./ \mathrm{ml}\right)$ is required for the formation of embryogenic cell clusters from single cells (Nomura and Komamine 1985), whereas a lower cell density $\left(2 \times 10^{4}\right.$ cells $\left./ \mathrm{ml}\right)$ favours the development of embryos from embryogenic cells (Fujimura and Komamine 1979). 


\section{Gene expression during carrot somatic embryogenesis}

Several biochemical changes were observed during somatic embryogenesis in carrot cultures. The rate of RNA and protein synthesis was greater in the embryogenic cultures of carrot (Chen and Luthe 1987). The relative rate of rRNA synthesis decreased, while the rate of poly (A) ${ }^{+}$RNA synthesis increased in embryogenic cultures. Other specific changes during carrot somatic embryogenesis were: the synthesis of two embryo specific proteins; increase in arginine decarboxylase activity; and increases in pyrimidine pathway enzyme activities.

Also a few changes were apparent in the abundant proteins that were synthesized in somatic embryos compared to callus cells (Sung and Okimoto 1981). These early studies can be optimistically interpreted as showing that at least a few changes in gene expression could be observed by protein analysis of embryo stages versus callus cells, and it was speculated that even more changes may have occurred in the production of less abundant proteins or mRNAs. Several groups took a similar approach in trying to identify "embryo-enhanced genes" from carrot somatic embryos. In sandalwood cultures, for example, the transition from primary callus (stage $0-S_{0}$ ) to $S_{1}$ involves a stage-specific appearance of 15 and $30 \mathrm{kDa}$ polypeptides along with an increase in the level of a polypeptide of $16 \mathrm{kDa}$ molecular mass. A $24 \mathrm{kDa}$ polypeptide which could be detected as a marked band in extracts from stage 0 was not detected in tissues of $S_{1}$, $S_{2}$ and $S_{3}$ embryos.

The basic experimental strategy, thus, relied on a comparison of genes and proteins being expressed in embryogenic and non-embryogenic calli as well as in the different stages of embryogenesis. Several of the genes that have been isolated from somatic embryos of carrot are summarized in table 1 .

\section{Expression of polarities in early stages of somatic embryogenesis}

The expression of polarity of active DNA synthesis as a means to understand embryogenesis was analysed during phases of carrot suspension cultures by threedimensional reconstruction of serial sections of $\left[{ }^{3} \mathrm{H}\right]$-thymidine pulse chase labelled, cells, using a computer (Komamine et al 1992). The different phases of carrot somatic embryogenesis used were earlier well characterized (Fujimura and Komamine 1980). In phase 0 of the system, embryogenic cell clusters are formed from competent single cells (state 0 ) in the presence of auxin. During this phase, the cell clusters gain the ability to develop into embryos when auxin is removed from the medium, giving rise to state 1 cell clusters. Phase 1 is thus induced by this process. During phase 1, cell clusters proliferate slowly and apparently without further differentiation. After phase 1, rapid cell division occurs in certain parts of the cell clusters, leading to the formation of globular embryos (phase 2). In phase 3, plantlets develop from globular embryos via heart- and torpedo-shaped embryos. Cell division is very rapid in phase 2 : the doubling time being $6.3 \mathrm{~h}$, whereas it is 51 and $36 \mathrm{~h}$ in phases 1 and 3, respectively. The polarity of DNA synthesis in cell clusters was confirmed during phases 1 and 2 using $\left[{ }^{3} \mathrm{H}\right]$ thymidine. However, the polarity was cancelled when cell clusters were cultured under non-embryogenic conditions, i.e., in the presence of auxin. Therefore, polarized rapid cell division or DNA synthesis is considered specific to embryogenesis. It was confirmed that DNA synthesis occurred randomly in the first 3 days of culture in the 
absence of auxin (phase 1), but polarized DNA synthesis was clearly observed during 3 to 4 days of culture (phase 2). This gave rise to globular embryos, in which high activity of DNA synthesis was observed in the procambial and proembryonal cells.

In state 2 cell clusters, polarized localization of actively DNA synthesizing cells was observed. The separation of actively DNA synthesizing cells (ADS cells) from nonactively DNA synthesizing ones (NDS cells) was attempted by density gradient centrifugation in percoll solution after maceration of cells to protoplasts to investigate the difference at the molecular level between ADS and NDS cells. Protein patterns were compared in both cells using sodium dodecylsulphate-polyacrylamide gel electrophoresis and $\left[{ }^{35} \mathrm{~S}\right]$ methionine. Three proteins were detected in ADS but not in NDS cells. These proteins can be candidates for markers of polarity of DNA synthesis specific for embryogenesis. Polarized localization of poly (A) ${ }^{+}$RNA was also detected in cell clusters at the end of phase 0 by in situ hybridization using $\left[{ }^{3} \mathrm{H}\right]$ poly (U). This polarity also disappeared when cell clusters were transferred to non-embryogenic conditions. Moreover, polarized localization of free calcium during embryogenesis was observed using a fluorescent calcium indicator, Fura 2.

\section{Gene expression in somatic embryogenesis systems of other species}

Little progress has been made in the biochemical and molecular investigation of somatic embryogenesis of other plant species, because of the difficulty in obtaining a system in which embryogenesis occurs at high frequency with synchrony. Nevertheless, somatic embryogenesis systems of other plant species are beginning to be used. In an analysis of proteins from embryogenic and non-embryogenic rice calli, Chen and Luthe (1987) have identified two embryo-specific polypeptides of 54 and $24 \mathrm{kDa}$ mass which corresponded to the major polypeptides in rice embryo extracts. One polypeptide of $22.7 \mathrm{kDa}$ was consistently present in the extracts from non-embryogenic calli. Ozawa et al (1992) have similarly related a specific $49 \mathrm{kDa}$ polypeptide to embryogenesis in a rice interspecific hybrid Fl (Oryza sativa $\times$ Oryza latifolia).

Isozyme modifications associated with the embryogenic potential of 10 sweet potato cultivars were determined (Cavalcante Alves et al 1994). The isozymes of esterase, peroxidase, glutamate oxaloacetate transaminase and acid phosphatase investigated in this study were found appropriate to distinguish compact embryogenic from friable non-embryogenic callus. The callus reversion was associated with a loss of bands or a decline in isozyme activity.

In a highly efficient synchronous embryogenesis induced in suspension cultures of sour orange (C. aurantium), the profiles of soluble cellular protein extracts of embryo and proembryogenic (PEM) cells were very similar as judged by two-dimensional Polyacrylamide gel electrophoresis. However, major differences were detected in the profiles of extracellular glycoproteins of 53-57 kDa mass and developing embryos accumulated at least 4 new extracellular polypeptides of 41-42 kDa mass (Gavish et al 1991). Coutos-Thevenot et al (1992) in their study of extracellular protein patterns of grapevine cell suspensions in embryogenic and non-embryogenic situations, identified specific proteins and glycoproteins $(66,62,56,51,48,36,32,25$ and $10 \mathrm{kDa})$, under negative control of auxin, as secreted during embryogenesis. It was also shown that the $36 \mathrm{kDa}$ glycoprotein excreted by grapevine embryos is a cationic peroxidase as in the 


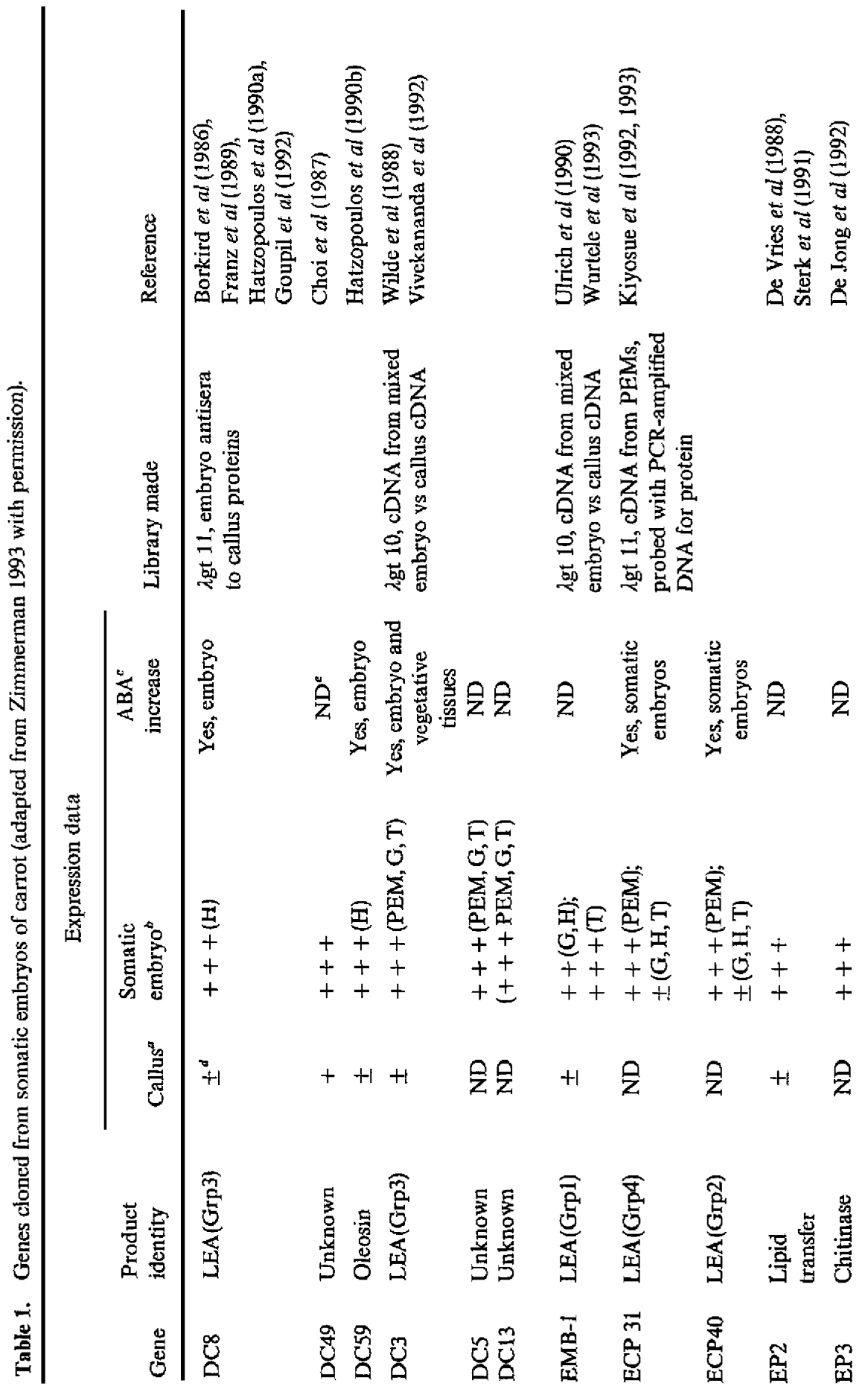




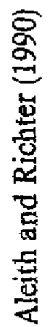

要吉总

是东里

용ㅋㅁ

合学总

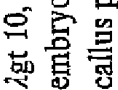

是 是是是是是

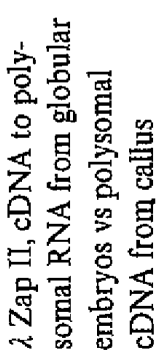

总熟器

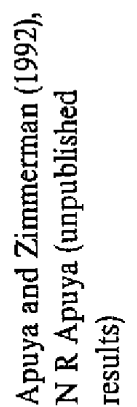

是

妾会

$F$

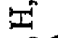

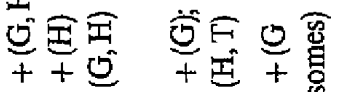

$++t+++t$

$+t++1+++\overrightarrow{8}$

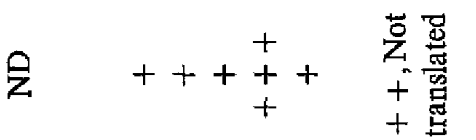

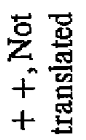

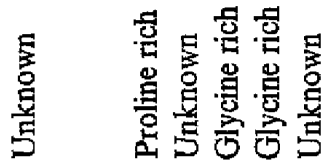

息兽总

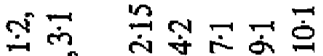

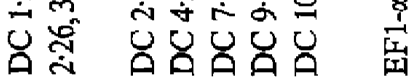

会

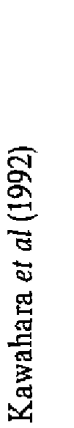

害

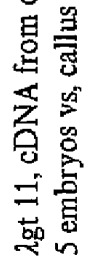

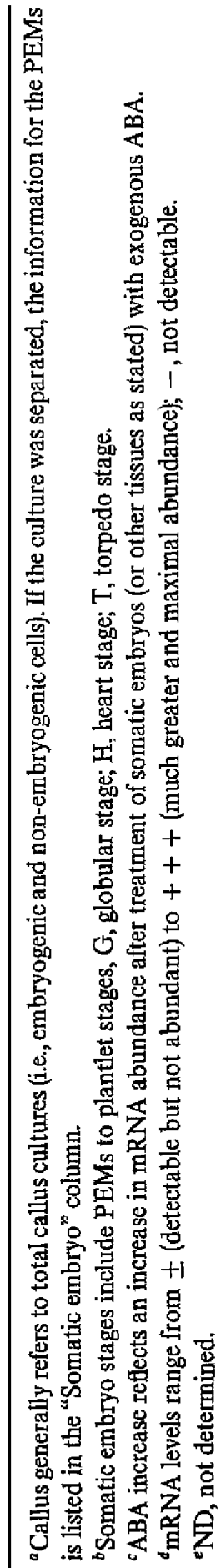


case of carrot model system whereas the $10 \mathrm{kDa}$ polypeptide immunoreacted with an antibody directed against a maize lipid transfer protein.

Riitta Puupponen-Pimiä et al (1993) identified and isolated a birch (Betula pendula Roth), embryogenic gene BP8 by heterologous hybridization using the carrot embryogenic gene DC8. The birch BP8 gene encodes a putative protein of $53 \mathrm{kDa}$ mass showing 52\% sequence identity with the DC8 gene at the amino acid level and contains 20 repeats of 11 amino acids and thus belongs to the group of LEA proteins isolated from such plants as cotton, wheat and carrot.

\section{Proteins secreted by somatic embryos}

Van Engelen and de Vries (1992) summarized the importance of extracellular proteins for the development of somatic embryos of angiosperms.

Media conditioned by plant cell cultures contain a complex array of molecules, mainly derived from the cell wall, including polysaccharides, proteoglycans and polypeptides. Among the latter are a large number of enzymes. It was observed that conditioned medium from somatic embryo cultures could promote somatic embryogenesis (Hari 1980; Smith and Sung 1985). In addition, it was shown that secreted extracellular proteins (EPs) could rescue embryogenesis in a temperature- sensitive (ts) variant carrot cell line (Lo Schiavo et al 1988; De Jong et al 1992). Observations have further indicated that cultured plant cells condition their medium with components that do influence cell proliferation and somatic embryo development in a more specific way. If an extracellular molecule is necessary for embryogenesis, it must be synthesized by the cells themselves. Exploiting the observation that important proteins appear to be secreted from carrot somatic embryo cultures, clones encoding some of these EPs were isolated (de Vries et al 1988; Sterk et al 1991). One of these clones, EP2 was identified as encoding a lipid transfer protein whose function was suggested to involve the transport of lipids or other apolar molecules out of cells. Other EPs, such as EP1 and EP3, have been similarly isolated from media of somatic embryo cultures (Van Engelen et al 1991; De Jong et al 1992). EP3 encodes a glycosylated acidic endochitinase (De Jong et al 1992) that is able to restore embryo development to a ts somatic embryo defective cell line, ts11. EP1 is not expressed in embryogenic cell clusters or somatic embryos but rather is produced by the non-embryogenic cells of the callus culture and has a homology with Brassica S locus glycoprotein genes (Van Engelen et al 1991; Van Engelen and de Vries 1992). It is suggested that these secreted proteins are likely to play a role in the regulation of cell expansion, which is critical to the maintenance of the integrity of the epidermal layer in embryos and to the proper establishment of shape and form, which is largely controlled by cell expansion (Van Engelen and de Vries 1992; Sterk and de Vries 1993).

In the grapevine (Vitis vinifera $\mathrm{cv}$ Chasselas $\times$ Vitis berlandieri) cell suspensions, it was shown that a $36 \mathrm{kDa}$ glycoprotein secreted into the medium is a cationic peroxidase as in the case of the carrot system whereas the $10 \mathrm{kDa}$ protein immunoreacted with an antibody raised against a maize lipid transfer protein (Coutos-Thevenot et al 1992). In sour orange (C. aurantium. ), extracellular proteins accumulated by PEM cells and those by developing embryos are different (Gavish et al 1991). The embryogenic potential in carrot can also be regulated by secreted arabinogalactan proteins (AGPs) (Kreuger and van Hoist 1993). AGPs are a heterogeneous group of proteoglycans 
present in cell walls and in plasma membranes and commonly found in culture media (Fincher and Stone 1983). Different plant organs contain characteristic sets of AGPs that are dependent on the developmental stage of the tissue (for review, see Pennell 1991). Changes in the presence of AGP-epitopes occur during development of carrot somatic embroys (Pennell et al 1991) and are reflected in the crossed-electrophoresis pattern of culture media AGPs (Kreuger and van Holst 1993). AGPs isolated from seed extracts of carrot were shown to have positive effects on the development of embryogenic cultures, while those from a non-embryogenic culture had a negative effect (Kreuger and van Holst 1993). Egertsdotter and von Arnold (1995) have shown that development of somatic embryos of the gymnosperm, Norway spruce (Picea abies) is also associated with particular extracellular AGPs, which have a regulatory function.

\section{Late embryogenesis abundant gene expression in somatic embryos}

Although somatic embryos do not desiccate and become dormant, they do synthesize and accumulate abscisic acid (ABA) and also express several genes that have been shown to be ABA inducible which code for a class of proteins called late embryogenesis abundant (LEA) proteins. LEA proteins are very hydrophilic proteins that are abundantly expressed late in zygotic embryogenesis in many plant species, including cotton (in which they were originally described), barley, rice, oilseed rape and wheat (Dure et al 1989). In zygotic embryos, they are believed to play a role in protecting the embryo during desiccation. The LEA genes of carrot somatic embryos include representatives of all four described groups of LEA proteins. All these proteins bear a significant homology in their amino acid composition or general protein structure (Dure et al 1989). In carrot, most of the LEA transcripts increase significantly in abundance in somatic embryos at the heart stage (Choi et al 1987; Wilde et al 1988; Franz et al 1989; Kiyosue et al 1992, 1993; Wurtele et al 1993) while some like ECP31 and ECP40, are highly expressed in the PEMs of callus cell cultures. LEAs are found to be the most abundant and differentially expressed mRNAs in somatic embryos, as compared to callus cells (Zimmerman 1993). All of the carrot LEA genes tested can be induced by ABA treatment of callus cells and somatic embryos (Hatzopoulos et al 1990; Goupil et al 1992; Kiyosue et al 1992, 1993; Vivekananda et al 1992). However, it appears that only DC3, a group 3 LEA, can be induced in non-embryogenic tissue by either ABA or desiccation stress, whereas the other LEAs that have been tested (DC8, DC59, ECP31, and ECP40) cannot be induced in non-embryogenic cells. Further information on LEA genes, the regulatory mechanisms governing their expression, the distribution and timing of EMB-1 LEA gene expression in somatic and zygotic embryos of carrot can be obtained from Thomas (1993) and Wurtele et al (1993).

In situ localization experiments have shown that the expression pattern of at least the EMB-1 gene in carrot somatic embryos is analogous to its expression pattern in zygotic embryos of carrot (Wurtele et al 1993). This result provides important validation of the use of somatic embryos as a model for embryogenesis.

A sandalwood homologue was identified for the wheat embryo LEA gene, pMA2005 by heterologous hybridization. Northern hybridization of mRNA isolated from sandalwood cells representing different stages of somatic embryos with pMA2005 probe gave intense signals, suggesting a high level of expression of the gene (K Sankara Rao and Subha Manna, unpublished results). 


\section{Molecular markers for cell differentiation in embryogenesis}

The usefulness of the somatic embryo system in studying development depends much on the generation of specific molecular markers for events leading to embryo development. Komamine et al (1992) detected several molecular markers viz., polypeptides, mRNAs, antigens against monoclonal antibodies in carrot synchronous embryogenic system. These markers which were detected during the process of expression of totipotency of cells in the system, disappear during loss of totipotency. Some of the genes that have been cloned from carrot somatic embryos, such as EP2 (table 1), have turned out to be useful markers of differentiation (of the dermal tissue system, in the case of EP2) as it is enhanced in expression in embryogenesis. It appears that callus cells, particularly the PEMs (preglobular embryogenic masses) contained in the callus express many of the genes that could represent potentially useful molecular markers, particularly for early events in embryogenesis.

Alternative approaches to the isolation of useful markers in embryo development are (i) the use of genes that have been cloned from other time points in development during which expression of the gene appears to be tissue or cell-type specific. For example, genes whose expression is localized to the vascular system in leaf tissue might be useful in identifying provascular cells in early embryos. The characterization of the expression patterns of such genes by in situ hybridization to embryo sections could be informative, (ii) identification of clones that are induced in globular or bipolar embryos as compared to young seedlings. Several undescribed or novel sequences that are enhanced in embryos compared to seedlings were identified (Zimmerman 1993). One such novel sequence was identified in sandalwood embryos viz., a homologue of a Cuscuta haustorial (organ-specific) gene (K Sankara Rao and Subha Manna, unpublished results).

\section{Expression of "non-embryogenic" genes during somatic embryogenesis}

Somatic embryogenesis systems have been used to assess the expression of genes isolated from non-embryogenic tissue. Particular attention has been focussed on both cell cycle genes and histone genes. Callus suspension cultures of alfalfa and the somatic embryos derived from them are proving useful in studying the relationship among auxins, the reactivation of rapid cell cycling and the induction of genes associated with the cell cycle (Hirt et al 1991).

\section{Signal molecules in somatic embryogenesis}

In plant embryogenesis, inductive interactions mediated by diffusible signal molecules are likely to be of great importance. The possibility of somatic plant cells in culture to acquire embryogenic potential has been exploited to establish experimental systems that allow the identification of molecules able to promote or influence the formation of somatic embryos. Recent evidence suggests that particularly purified AGPs isolated from the culture medium of embryogenic Daucus lines and from dry Daucus seeds were able to promote the formation of proembryogenic masses, even in previously nonembryogenic Daucus cell lines, when added in nanomolar concentrations. Other AGPs, isolated from the medium of a non-embryogenic line, acted negatively on the formation 
of proembryogenic masses (Kreuger and van Holst 1993). These results show that specific members of the family of AGPs are involved in the formation of embryogenic clusters. These AGPs though totally different from conventional plant growth regulators are considered likely candidates for molecules able to mediate developmental processes in plants, perhaps by a cell-inductive mechanism (Pennell et al 1991). Recently De Jong et al (1992) have identified a $32 \mathrm{kDa}$ endochitinase able to lift the arrest in embryo development of the temperature-sensitive carrot variant ts 11. Later De Jong et al (1993) have shown that chitin-containing bacterial signal molecules, Nod factors, are able to mimic the effect of the $32 \mathrm{kDa}$ endochitinase. These results suggest that the $32 \mathrm{kDa}$ endochitinase is involved in the generation of plant analogues of the signal molecules.

\section{Prospects}

The complex process of plant embryogenesis is now being understood slowly. General differential screening approaches and other experimental strategies have allowed the isolation of a small number of genes that are up regulated in somatic embryos. The somatic embryo system has only begun to reveal its potential for generating valuable information towards understanding the regulation of gene expression required for the earliest developmental events in the life of a higher plant.

Somatic embryos can further allow analyses of transcriptional versus post- transcriptional regulation through quantitative nuclear run-off measurements and analysis of polysomal versus total RNAs (Zimmerman 1993). Important clues about the processes involved in embryo morphogenesis may also be obtained from analyses of embryonic mutants. One genetic approach has been shown to be potentially useful in dissecting events in somatic embryogenesis viz., the identification and characterization of conditional mutants.

\section{Acknowledgements}

Research on sandalwood somatic embryogenesis has been made possible with support from the Indian Council of Agricultural Research, Department of Science and Technology and Department of Biotechnology, New Delhi. The cDNA clones of Cuscuta pARIS CH. 11 and Wheat pMA2005 are gifts from Prof. S Mahadevan and Dr. Walker-Simmons.

\section{References}

Bacchi O 1943 Cytological observation in Citrus. III Megasporogenesis, fertilization, and polyembryony; Bot. Gaz. 105 221-225

Backs-Hüsemann D and Reinert J 1970 Embryobildung durch isolierte einszellen aus gewebekulturen von Daucus carota; Protoplasma 70 49-60

Cavalcante Alves J M, Sihachakr D, Allot M, Tizroutines, Mussio I, Servaes A and Ducreux G 1994 Isozyme modifications and plant regeneration through somatic embryogenesis in Sweet Potato (Ipomoea batatas (L.) Lm.); Plant Cell Rep. 13 437-441

Chen L J and Luthe D S 1987 Analysis of proteins from embryogenic and non-embryogenic rice (Oryza sativa L.) calli; Plant Sci. 48 181-188

Choi J H, Lin L S and Borkird C 1987 Isolation of cDNA clones for rare embryo-specific antigens in carrot cell cultures; Proc. Natl. Acad. Sci. USA 84 1906-1910 
Coutos-Thevenot P, Maes O, Jouenne T, Mauro M C, Boulay M, Deloire A and Guern J 1992 Extracellular protein patterns of grapevine cell suspensions in embryogenic and non-embryogenic situations; Plant Sci. 86 137-145

De Jong A J, Cordewener J, Lo Schiavo F, Terzi M, Vandekerekhove J, Van Kammen A and de Vries S C 1992 A Carrot somatic embryo mutant is rescued by chitinase; Plant Cell 4 425-433

De Jong A J, Schmidt E D L and de Vries S C 1993 Early events in higher plant embryogenesis; Plant Mol. Biol. 22 367-377

de Vries S C, Booij H, Meyerink P, Huisman G, Wilde D H, Thomas T L and Van Kämmen A 1988 Acquisition of embryogenic potential in carrot cell suspension cultures; Planta 176 196-204

Dudits D, Bogre L and Gyorgyey J 1991 Molecular and cellular approaches to the analysis of plant embryo development from somatic cells in vitro; J. Cell Sci. 99 475-484

Dure L III, Crouch M, Harada J, HO T-HD, Mundy J, Quatrano R, Thomas T and Sung Z R 1989 Common amino acid sequence domains among the LEA proteins of higher plants; Plant Mol. Biol. 12 475-486

Egertsdotter U and von Arnold 1995 Importance of arabionogalactan proteins for the development of somatic embryos of Picea abies; Physiol. Plant. 93 334-345

Fincher G B and Stone B A 1983 Arabinogalactan-proteins: Structure, biosynthesis and function; Annu. Rev. Plant. Physiol. 34 47-70

Franz G, Hatzopoulos P and Jones T J 1989 Molecular and genetic analysis of an embryogenic gene, DC8, from Daucus carota L; Mol. Gen. Genet. 218 143-151

Fujimura T and Komamine A 1979 Synchronization of somatic embryogenesis in a carrot cell suspension culture; Plant Physiol. 64 162-164

Fujimura T and Komamine A 1980 The serial observation of embryogenesis in a carrot cell suspension culture; New Phytol. 86 213-218

Gavish H, Vardi A and Fluhr R 1991 Extra-cellular proteins and early embryo development in Citrus nucellar cell cultures; Physiol. Plant 82 601-616

Giuliano G, Rosellini D and Terzi M 1983 A new method for the purification of the different stages of carrot embryos; Plant Cell Rep. 2 216-218

Goupil P, Hatzopoulos P, Franz G, Hempel F D, You R and Sung Z R 1992 Transcriptional regulation of a seed-specific carrot gene, DC 8; Plant Mol Biol. 18 1049-1063

Hari V 1980 Effect of cell density changes and conditioned media on carrot cell embryogenesis; $Z$. Pfianzenphysiol. 96 227-231

Hatzopoulos P, Fong F and Sung Z R 1990 Abscisic acid regulation of DC 8, a carrot embryogenic gene; Plant Physiol. 94 690-695

Hirt H, Pay A, Györgyey J, Bako L, Nemeth K, Bögre L, Schweyen R J, Heberle-Bors E and Dudits D 1991 Complementation of a yeast cell cycle mutant by an alfalfa cDNA encoding a protein kinase homologous to $\mathrm{p}^{34 c d c 2 ;}$ Proc. Natl. Acad. Sci. USA 88 1636-1640

Johri B M 1984 Embryology of Angiosperms (Berlin: Springer-Verlag)

Kiyosue T, Yamaguchi- Schinozaki K, Shinozaki K, Higashi K, Satoh S, Kamada H and Harada H 1992 Isolation and characterization of a cDNA that encodes ECP31, an embryogenic-cell protein from carrot; Plant Mol. Biol. 21 1053-1068

Kiyosue T, Yamaguchi- Schinozaki K, Schinozaki K, Kamada H and Harada H 1993 cDNA cloning of ECP40, an embryogenic cell protein in carrot and its expression during somatic embryogenesis; Plant Mol. Biol. 19 239-249

Komamine A, Kawahara M, Matsumoto M, Sunabori S, Toya T, Fujiwara A, Tsukahara M, Smith J, Ito M, Fukuda H, Nomura K and Fujimura T 1992 Mechanisms of somatic embryogenesis in cell cultures; Physiology, Biochemistry and Molecular Biology; In Vitro Cell Dev. Biol. 28P 11-14

Kreuger M and van Holst G J 1993 Arabinogalactan proteins are essential in somatic embryogenesis of Daucus carota L; Planta 189 243-248

Liu C-M, Xu Z-h and Chua N-H 1993 Auxin polar transport is essential for the establishment of bilateral symmetry during early plant embryogenesis; Plant Cell 5 621-630

Lo Schiavo F 1984 A critical review of the procedures for embryo purification; Plant Mol. Biol. Rep. 2 15-18

Lo Schiavo F, Giuliano G and Sung Z R 1988 Characterization of a temperature-sensitive cell mutant impaired in somatic embryogenesis; Plant Sci. 54 157-164

Mayer U, Torres Ruiz R A, Berleth T, Misera S and Jürgens G1991 Mutations affecting body organization in the Arabidopsis embryo; Nature (London) 353 402-407

Nomura K and Komamine A 1985 Identification and isolation of single cells that produce somatic embryos at a high frequency in carrot suspension culture; Plant Physiol. 79 988-991 
Ozawa K, Ling D H and Komamine A 1992 A two-dimensional electrophoretic analysis of protein during somatic embryo formation in cell suspension cultures of Oryza; in World Congress on Cell and Tissue Culture, Arlington, VA (Washington, DC) p 129A

Penneil R I 1992 Cell surface arabinogalactan proteins, arabinogalactans and plant development, in Society for Experimental Biology Seminar series 48: Perspectives in Plant cell Recognition (eds) J A Callow and J R Green (Cambridge: Cambridge University Press) pp 105-121

Pennell R I, Janniche L, Kjellbom P, Scofield G N, Peart J M and Roberts K 1991 Developmental regulation of a plasma membrane arabinogalactan protein epitope in oilseed rape flowers; Plant Cell 3 1317-1326

Reinert J 1958 Morphogenese und ihre Kontrolle an Gewebekulturen aus Carotten; Naturwissenschaft 45 344-345

Riitta Puupponen-Pimiä, R, Saloheimo M, Vasara T, Ra R, Gaugecz J, Kurten U, Knowles J K C, Keränen S and Kauppinen V 1993 Characterization of a birch (Betula pendula Roth.) embryogenic gene, BP8; Plant Mol. Biol. 23 423-428

Smith J A and Sung Z R 1985 Increase in regeneration of plant cells by cross feeding with regenerating Daucus carota cells; in Somatic embryogenesis (eds) M Terzi, L Pitto and Z R Sung (Rome: IPRA) pp 133-136

Steeves T A and Sussex I M (eds) 1989 Patterns in plant development 2nd edition (Cambridge: Cambridge University Press)

Sterk P, Booij H, Schellekens G A, Van Kämmen A and De Vries S C 1991 Expression pattern of carrot EP2 gene encoding an extracellular lipid transfer protein; Plant Cell. 3 907-921

Sterk P and de Vries S C 1993 Molecular markers for plant embryos; in Synseeds: Application of synthetic seeds to crop inprovement (ed.) K Redenbaugh (Boca Raton, FL: CRC Press)

Steward F C, Mapes M O and Smith J 1958 Growth and organized development of cultured cells. Growth and division of suspended cells; Am. J. Bot, 45 693-703

Sung Z R and Okimoto R 1981 Embryogenic proteins in somatic embryos of carrot; Proc. Natl. Acad. Sci. USA 78 3683-3687

Thomas T L 1993 Gene expression during plant embryogenesis and germination: An overview; Plant Cell 5 1401-1410

Van Engelen F A and de Vries S C 1992 Extracellular proteins in plant embryogenesis; Trends Genet. 8 66-70

Van Engelen F A, Sterk P, Booij H, Cordewener J H G, Rook W Van Kämmen A and de Vries S C 1991 Heterogeneity and cell type-specific localization of a cell wall glycoprotein from carrot suspension cells; Plant Physiol. 96 705-712

Vivekananda J, Drew M C and Thomas T L 1992 Hormonal and environmental regulation of carrot lea-class gene DC3; Plant Physiol. 100 576-581

Warren G S and Fowler M W 1977 A Physical method for the separation of various stages in the embryogenesis of carrot cell cultures; Plant Sci. Lett. 9 71-76

Wilde H D, Nelson W S and Booij H 1988 Gene expression programs in embryogenic and non-embryogenic carrot cultures; Planta 176 205-211

Williams E G and Maheswaran 1986 Somatic embryogenesis: Factors influencing coordinated behaviour of cells as an embryogenic group; Ann. Bot. 57 443-462

Wurtele E S, Wang H, Durgerian S, Nikolan B J and Ulrich T H 1993 Characterization of a gene that is expressed early in somatic embryogenesis of Daucus carota; Plant Physiol. 102 303-312

Zimmerman J L 1993 Somatic embryogenesis: A model for early development in higher plants; Plant Cell 5 1411-1423. 